DOI: $10.1037 / 20019362$

\title{
Spontaneous Remission From PTSD Depends on the Number of Traumatic Event Types Experienced
}

\author{
Iris-Tatjana Kolassa, Verena Ertl, and Cindy Eckart \\ University of Konstanz
}

Lamaro P. Onyut

University of Konstanz and Mbarara University of Science and Technology

\author{
Stephan Kolassa \\ Research \& Innovation, SAF Simulation, Analysis \& \\ Forecasting AG, Tägerwilen, Switzerland
}

Thomas Elbert
University of Konstanz

\begin{abstract}
As exposure to different types of traumatic stressors increases, the prevalence of PTSD increases However, little is known about the effects of cumulative exposure to traumatic stress on the maintenance and remission from PTSD. In 2006/2007, we investigated 444 refugees from the 1994 Rwandan genocide, assessing exposure to traumatic events, current and lifetime PTSD, and PTSD symptom severity. Higher trauma exposure was associated with higher prevalence of current and lifetime PTSD, with lower probability of spontaneous remission from PTSD, and with higher current and lifetime PTSD symptom severity in clear dose-response effects. The results suggest traumatic load as a root cause of both PTSD chronicity and symptom severity and support the hypothesis of a neural fear network in the etiology of PTSD.
\end{abstract}

Keywords: PTSD, remission, dose-response, chronic, trauma

Traumatic stress refers to potentially harmful experiences eliciting feelings of helplessness, intense fear, or horror, with an associated alarm response leading to the acute release of stress hormones (cf. Elbert, Rockstroh, Kolassa, Schauer, \& Neuner, 2006). Individuals who have experienced traumatic stress once in their life are likely to become victims of threatening events again (Green et al., 2000; McCauley et al., 1997). Thus, the effects of multiple traumatization on psychological well-being have attracted increasing interest. It has repeatedly been shown in this context that the experience of repeated traumatic stress renders a person more vulnerable to develop posttraumatic stress disorder (PTSD) in a cumulative manner (El Sarraj, Punamäki, Salmi, \& Summerfield, 1996; Johnson \& Thompson, 2008; Mollica et al., 1998; Mollica, McInnes, Poole, \& Tor, 1998). However, the finding of a dose-response effect for PTSD has remained controversial, partic-

Iris-Tatiana Kolassa, Clinical Psychology \& Neuropsychology, University of Konstanz, and Zukunftskolleg, University of Konstanz; Verena Ertl, Cindy Eckart, and Thomas Elbert, Clinical Psychology \& Neuropsychology, University of Konstanz; Stephan Kolassa, Research \& Innovation, SAF Simulation, Analysis \& Forecasting AG, Tägerwilen, Switzerland; Lamaro P. Onyut, Clinical Psychology \& Neuropsychology, University of Konstanz, and Mbarara University of Science and Technology.

This study was funded by the German Research Foundation (DFG), and a stipend of the Zukunftskolleg of the University of Konstanz awarded to ITK. We thank Franka Glöckner for her support in data collection.

Correspondence concerning this article should be addressed to IrisTatjana Kolassa, Emmy Noether Junior Research Group, Department of Psychology, University of Konstanz, Universitätsstr. 10, 78457 Konstanz, Germany. E-mail: iris.kolassa@uni-konstanz.de ularly as retrospective self-reports may be affected by clinical state (McNally, 2003).

A possibility of resolving this problem lies in categorizing the exposure to different traumatic stressors and violence. Several approaches have been reported in this context: A prevalent distinction focuses on the quality of traumatic events and categorizes them according to being assaultive (interpersonal) or nonassaultive (noninterpersonal) - indeed, the experience of repeated interpersonal events was associated with a higher incidence of PTSD than the experience of noninterpersonal traumatic stress (Breslau et al., 1998; Green et al., 2000). Another categorization scheme focuses on the stage of life in which the traumatic stress has been experienced and separates childhood abuse from traumatization during adulthood-different types of childhood abuse were cumulatively associated with later psychiatric disturbances (Edwards, Holden, Felitti, \& Anda, 2003; Lang, Stein, Kennedy, \& Foy, 2004) and these disturbances were most intense if an initial childhood abuse was subsequently followed by further assaults in adulthood (Breslau, Chilcoat, Kessler, \& Davis, 1999; Folette, Polusny, Bechtle, \& Naugle, 1996; McCauley et al., 1997). Besides these conceptual approaches, it has repeatedly been shown that a strong cumulative influence of the sum of different traumatic event types (e.g., being beaten, witnessing someone being murdered, etc.) on PTSD development and/or symptom severity exists independently of presupposed broader categories (Dohrenwend et al., 2006; Kolassa \& Elbert, 2007; Kolassa et al., 2010a; Neuner et al., 2004). We have referred to this cumulative or additive effect of traumatic event types contributing to the development of PTSD over time as a "building block effect" (Schauer et al., 2003).

The essential questions in the development and maintenance of PTSD are who develops PTSD after experiencing a traumatic 
event and who does not? And which factors influence how some people show chronic symptoms of PTSD over years and even decades while a substantial proportion, ranging from around $65 \%$ (Karamustafalioglu et al., 2006) to around 50\% (Perkonnig et al., 2005) recover without any form of treatment? A small number of factors associated with a chronic course of the disease has been identified so far, for example, an initially high level of avoidance symptoms (Karamustafalioglu et al., 2006; Perkonnig et al., 2005) and the occurrence of new traumatic events (Perkonnig et al., 2005 ) or stressors that reactivate the trauma memory (Kolassa, Burla, Schauer, \& Elbert, 2010).

\section{Factors Influencing the Maintenance of and Remission From PTSD}

As mentioned above, a significant proportion of PTSD sufferers seems to remit over time, even without any treatment. Multiple studies have investigated the factors influencing remission from PTSD after single traumatic events. A closer look, however, indicates that previously experienced traumatic stress and exposure to violence, including domestic violence, has often not or not properly been assessed. After motor vehicle accidents, higher initial symptom severity scores (measured with the CAPS, Blake et al., 1990), new traumas to family members, more severe physical injuries, and unremitted physical injuries four months after the initial diagnosis were associated with lower rates of remission from PTSD six months after the initial diagnosis (Blanchard et al., 1997). A study of patients in primary care with PTSD found that remission during 2-year follow-up was associated with lower comorbid anxiety disorders and higher psychosocial functioning at intake (Zlotnick et al., 2004). In a population of victims of physical and sexual assault, maintenance of PTSD was higher if the victim had held negative trauma sensitive beliefs prior to the assault, if the victim experienced mental defeat or mental confusion during the trauma, or if the victim exhibited a negative appraisal of initial posttrauma symptoms or avoidance or safety seeking as a maladaptive control strategy after the trauma (Dunmore, Clark, \& Ehlers, 2001). Finally, a higher total number and severity of PTSD symptoms, comorbid anxiety, or affective disorders and a family history of antisocial behavior and female sex differentiated patients with chronic PTSD from cases of remission in a sample of urban youths (Breslau \& Davis, 1992). Conversely, no predictive power of demographic characteristics, pretraumatic and acute psychiatric comorbities, nor exposure characteristics were found in survivors of a mass shooting after 6-8 weeks and 1 year (North, Smith, \& Spitznagel, 1997).

While previous studies point to a predictive power of PTSD symptom severity after trauma as well as of the severity of physical injury for the probability of spontaneous remission, most investigators unaware of the building block effect for PTSD did not control for the number of different event types experienced. In contrast, Mollica et al. (1998) present one of the few reports that indicate that cumulative exposure affects PTSD symptoms even a decade after the trauma. Consequently, we hypothesized a building block effect also for spontaneous remission from PTSD: A higher number of traumatic events experienced should lead to a lower probability of remission.

\section{Methods}

The Nakivale Refugee Settlement is located in southwestern Uganda. In 03/2006-02/2007, we investigated 444 refugees (238 male, 206 female; mean age $=34.77$ years, $S D=5.78$, age range 17 -68 years) from the Rwandan conflicts in the early 1990 s living in the camp. Most participants reported exposure to severe traumatic stressors, for example, witnessing killing or murder, seeing dead or mutilated bodies, shelling or bombing, or witnessing weapon injuries. The procedures were approved by the Ethics Committee of the University of Konstanz, Germany, and the Mbarara University of Science and Technology, Mbarara, Uganda. After complete description of the study, participants gave written informed consent.

Participants were examined using the Posttraumatic Diagnostic Scale (PDS, Ertl et al., in press; Foa, Cashman, Jaycox, \& Perry, 1997; Neuner et al., 2008). The PDS is a 17-item questionnaire widely used for the diagnosis of PTSD as well as the assessment of PTSD symptom severity. Each item corresponds to one of the PTSD symptoms specified in $D S M-I V$, and ratings range from 0 (never) to 3 (5 times per week or more/very severe/nearly always). Both lifetime and current PTSD were diagnosed using the PDS. To assess lifetime PTSD, participants were asked for each item of the PDS whether the specific symptom had ever occurred to a severity necessary to fulfill the requirement for a current symptom (a rating of at least 1, a standard cut-off suggested by Foa et al., 1997). The symptom was coded fulfilled (1) or not fulfilled (0), without specifically quantifying lifetime symptom severity (which was judged to be subject to distorted memory effects, leading to unreliability).

Traumatic event types experienced were assessed with a checklist of 31 war- and non-war-related traumatic event types, for example, injury by weapon, rape, accidents (de Quervain et al., 2007; Neuner et al., 2004), where each traumatic event type was scored 0 (not experienced) or 1 (experienced) before summation. Again, the number of times a specific event had been experienced was not assessed, as distorted memory in PTSD renders this measure unreliable (Elbert \& Schauer, 2002; Foa \& Riggs, 1993; Kolassa \& Elbert, 2007; McNally, 2006). In a previous study at the Nakivale camp in 2003 , the event list showed a high test-retest reliability $(r=.73, p<.001)$ and significant accordance with the CIDI Event List (Ertl, 2008).

The PDS and event list were completed in form of a standardized interview. Interviewers were German psychologists supported by local interviewers and translators-refugees resident in the camp-that have been extensively trained in a 6-week course on the principles of quantitative data collection and interviewing techniques (for details on the selection and training procedures see Onyut et al., 2004). Interviewers and translators that supported the present data collection were experienced in the work with traumatized individuals, as all of them had already worked under supervision in several epidemiological and treatment studies prior to this investigation (Eckart, Engler, Riether, Elbert, \& Kolassa, 2009; Kolassa et al., 2010a; Neuner et al., 2008; Onyut et al., 2009). Instruments were translated into Kinyarwanda using several steps of translations, blind back-translations, and subsequent corrections by independent groups of translators (Onyut et al., 2004). Following the translations, the psychometric properties of the translated scales were investigated in a validation study, including a retest 
spanning a 2-week period and a cross-validation with expert rating: A random selection of diagnoses of the trained interviewers was repeated by German psychologists and consistency between ratings was evaluated (Neuner et al., 2008).

All but one subject had experienced at least one event fulfilling the A1- and A2-criterion according to DSM-IV for a traumatic event. On average, participants had experienced 12.04 different traumatic event types $(S D=4.89$, range $0-24)$. Three hundred fifty-nine participants ( $80.9 \%$ of the sample) fulfilled criteria for lifetime PTSD, and 220 participants (49.5\%) fulfilled criteria for current PTSD, according to the Diagnostic and Statistical Manual of Mental Disorders, Fourth Edition (DSM-IV, American Psychiatric Association, 1994), as measured by the PDS. Participants with lifetime PTSD were included in an analysis of the probability of remission from PTSD. Remission was coded 0 (for participants suffering from both lifetime and current PTSD) or 1 (for participants suffering from lifetime but not current PTSD). None of the subjects had had pharmacological or psychotherapeutic intervention for PTSD, as no psychotherapeutic infrastructure is available.

\section{Statistics}

Dependent variables were analyzed using logistic or regular linear regressions using the software package $\mathrm{R}$ ( $\mathrm{R}$ Development Core Team, 2008). Nested models-models including trauma load versus models excluding it-were compared using likelihood ratio $(L R)$ tests (Harrell, 2001). Statistical significance as assessed using standard $\chi^{2}$ distributional assumptions was scrutinized using nonparametric permutation tests with 10,000 random permutations (Good, 2005). As $p$ values did not differ between parametric and nonparametric tests, parametric $p$ values are reported below. All reported $p$ values for $L R$ tests are one-tailed. The stability of fitted dose-response curves was assessed through full nonparametric bootstraps with 10,000 bootstrap samples.

\section{Results}

Higher numbers of different lifetime traumatic event types were associated with a higher probability of lifetime PTSD, Likelihood Ratio $(L R) 41.97, d f=1, p<.0001$. One additional traumatic event type experienced was associated with a $19 \%$ increase in the probability of developing lifetime PTSD, odds ratio $(O R) 1.19$, $95 \%$ confidence interval $(C I) 1.13 ; 1.26$ (see Figure 1a). Higher numbers of different lifetime traumatic event types were also associated with a higher probability of current PTSD, $L R=35.99$, $d f=1, p<.0001, O R=1.13, C I=1.08 ; 1.18$ (see Figure 1b), a lower probability of remission from lifetime PTSD, $L R=11.95$, $d f=1, p=.0005, O R=.92, C l=.88 ; .97$ (see Figure 2), a higher lifetime PDS sum score, $L R=57.76, d f=1, p<.0001$, regression coefficient $\beta=.25, C I=.19 ; .31$ (see Figure 3a), and a higher current PDS sum score, $L R=32.71, d f=1, p<.0001, \beta=.57$, $C I=.38 ; .77$ (see Figure $3 \mathrm{~b})$

\section{Discussion}

The results show a clear dose-response effect of traumatic load on the probability of long-term spontaneous remission from PTSD: Higher cumulative exposure to traumatic events is associated with a lower probability of remission, with an additional traumatic event type experienced associated with an $8 \%$ lower chance of spontaneous remission from PTSD. In addition, this study confirmed previous findings of dose-response effects, with higher numbers of traumatic event types experienced associated with
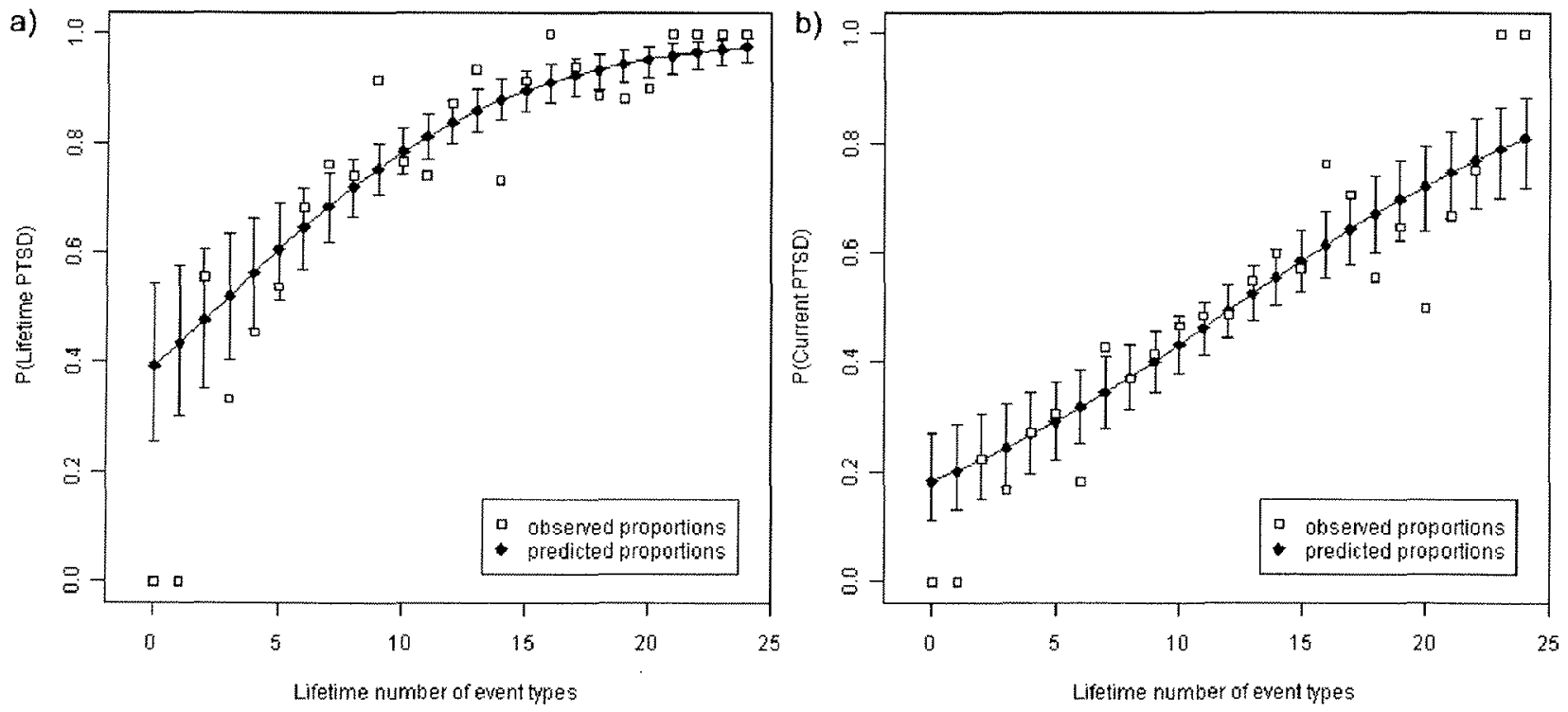

Figure 1. a) Proportion of participants with lifetime PTSD and fitted values against lifetime number of event types, with bootstrapped pointwise $95 \%$ confidence intervals for fitted values. b) Proportion of participants with current PTSD and fitted values against lifetime number of event types, with bootstrapped pointwise $95 \%$ confidence intervals for fitted values. 


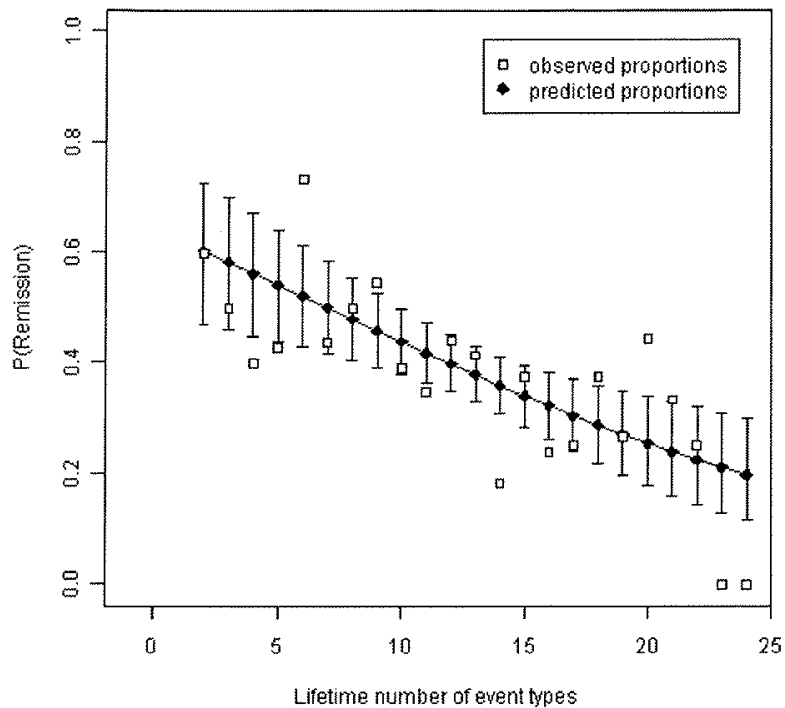

Figure 2. Proportion of participants having remitted from lifetime PTSD and fitted values against lifetime number of event types, with bootstrapped pointwise $95 \%$ confidence intervals for fitted values. Note. as there were no participants with 0 or 1 traumatic event and lifetime PTSD, there are no observed proportions for these values. We consequently refrained from extrapolating the model fit beyond observed values of traumatic load.

higher probabilities of developing lifetime and current PTSD as well as higher severity of lifetime and current PTSD symptoms.

The present results are in accord with previous studies on factors influencing development and maintenance of PTSD (Blanchard et al., 1997; Breslau \& Davis, 1992; Dunmore et al., 2001), which agreed in finding a strong negative association between both severity of traumatic experiences (e.g., severity of physical injury) and severity of PTSD symptoms and the probability of remission. The strong dose-response effect of traumatic load on both symptom severity and probability of spontaneous remission found in the present study suggests that the association between higher symptom severity and lower probability of remission found in previous studies may, in fact, be an artifact of more intense traumatization causing both higher symptom severity and lower remission probability. This may simplify current models of the etiology of PTSD.

Building on the earlier work of Lang $(1979,1984)$; Foa and Kozak (1986) proposed that the experience of a traumatic event results in the formation of a fear network in memory. Accordingly, attempts to connect the cognitive and emotional characteristics of PTSD with their corresponding neural underpinnings, focused mainly on a neural set of connections that was suggested to be associated with fear conditioning and general memory processes in healthy individuals and the animal model. This set mainly consists of amygdala, hippocampus, and medial prefrontal cortex. Disturbances in the interplay of these structures have been hypothesized to be responsible for the emergence of PTSD symptoms (Bremner, 2007; Brewin, 2001; Rauch, Shin, \& Phelps, 2006). Based on knowledge about the different effects of stress particularly on the functioning of hippocampus and amygdala (Metcalfe \& Jacobs, 1996), it has been posited that under extreme traumatic stress a neural fear network is created, which is further strengthened and extended in response to each new traumatic event: During a traumatic event, perceptual, cognitive, and emotional features of the situation together with the physiological response pattern are stored in memory, forming the nucleus of a network associated with the traumatic event. In line with basic assumptions concerning the organization of fear networks (Foa \& Kozak, 1986),
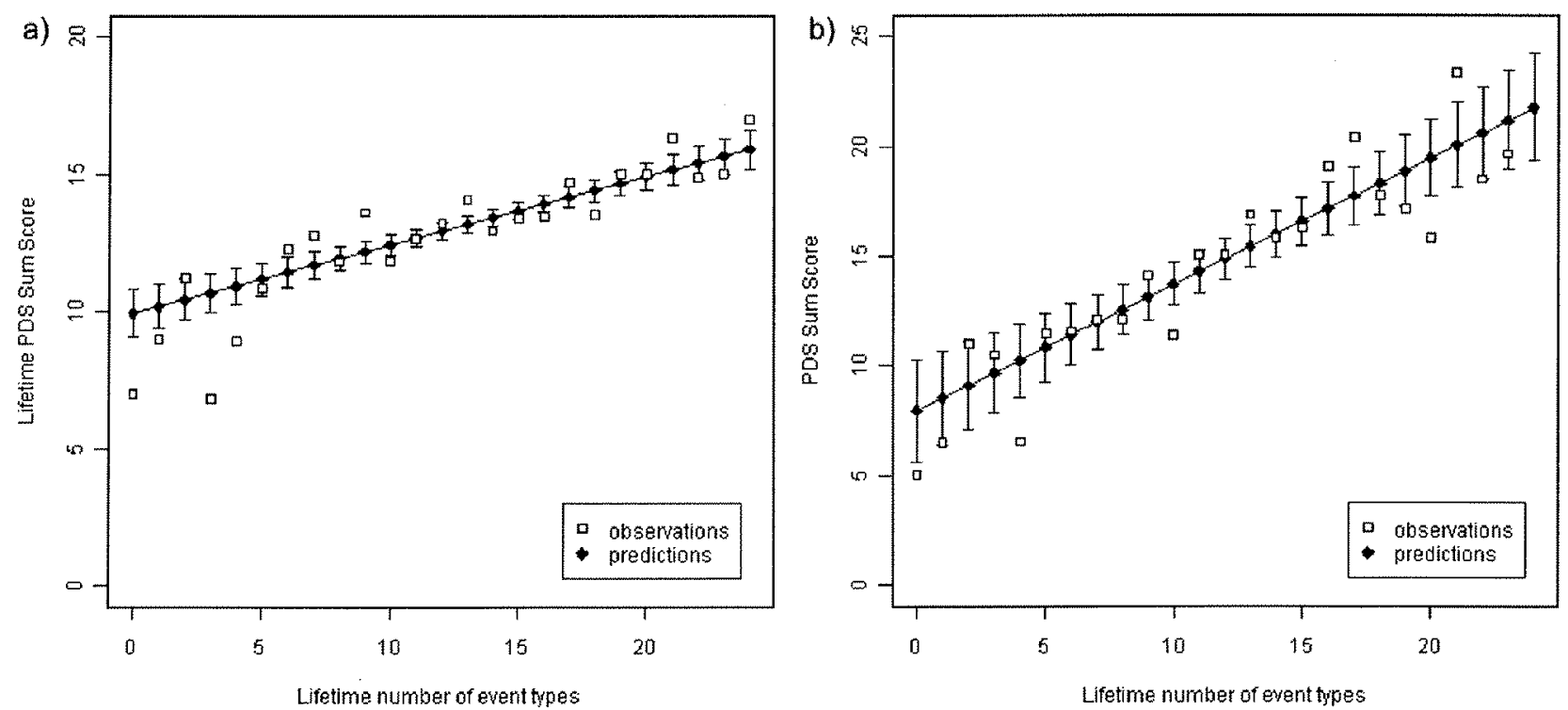

Figure 3. a) Mean lifetime PDS sum scores and fitted values against lifetime number of event types, with bootstrapped pointwise $95 \%$ confidence intervals for fitted values. Note, lifetime PDS items were coded 0 ("not fulfilled") and 1 ("fulfilled"), not $0-3$ as in the original PDS. b) Mean current PDS sum scores and fitted values against lifetime number of event types, with bootstrapped pointwise $95 \%$ confidence intervals for fitted values. 
subsequent traumatic events will become associated with similar mostly implicit memories, leading to the integration of additional knots into the existing fear network. Network connections are strengthened through synchronous activation via long-term potentiation: Neural assemblies firing repeatedly in synch will tend to become associated, so that activity in one facilitates activity in the other (Elbert et al., 2006; Kolassa \& Elbert, 2007). Our finding of a dose-response effect of successive traumatization appears to support this model on a behavioral basis. The more traumatic memories a fear network contains, the more stable it will become and the less probable will a spontaneous dissolution of the fear network - corresponding to spontaneous remission of PTSD-be. Indeed, the experience of new traumatic events has been the most robust predictor of a chronic course of PTSD in a longitudinal study on traumatized adolescents (Perkonigg et al., 2005).

The strengths of this study are a) the assessment of long-term remission prospects after traumatization during the 1994 Rwandan genocide, as neither pharmacological nor psychotherapeutical treatment was available in the refugee camp, b) the investigation of a severely traumatized sample with up to 24 different traumatic event types experienced, allowing to model dose-response effects in a way impossible in Western samples, and c) the examination of a very large sample, compared to previous studies.

There are, however, also some limitations to this study. The study was conducted retrospectively and thus is subject to the typical criticism of retrospective, cross-sectional studies concerning reliability of retrospective memories. As is common in PTSD studies on war-related traumatization, traumatic events were not objectively measured, as is easier, for example, in survivors of motor vehicle accidents. However, a building block effect on PTSD prevalence has also been found in studies using records of exposure to trauma independent of reports of the survivor (e.g., Dohrenwend et al., 2006). Together with the reliability and validity of the instruments established in the same camp (Ertl, 2008) and the strength and stability of the relationships found in the present study, this leaves us confident that the present results are not due to retrospectivity artifacts.

Future studies should address additional factors that may influence PTSD remission, while controlling for the number of traumatic event types experienced. Examples are genetic factors that may explain additional variance in both development and maintenance of PTSD (Kolassa et al., 2010b). In addition, it would be worthwhile to investigate whether the success of psychopharmacological or psychotherapeutic interventions is also modulated by traumatic load, which, however, would require similar sample sizes as the present study.

\section{References}

American Psychiatric Association. (1994). Diagnostic and statistical manual of mental disorders (4th ed.). Washington, DC: Author.

Blake, D., Weathers, F., Nagy, L., Kaloupek, D., Klauminzer, G., Charney, D., \& Keane, T. (1990). Clinician Administered PTSD Scale (CAPS). Boston, MA: National Center for Posttraumatic Stress Disorder, Behavioral Science Division-Boston.

Blanchard, E. B., Hickling, E. J., Forneris, C. A., Taylor, A. E., Buckley, T. C., Loos, W. R., \& Jaccard, J. (1997). Prediction of remission of acute posttraumatic stress disorder in motor vehicle accident victims. Journal of Traumatic Stress, 10(2), 215-234.

Bremner, J. D. (2007). Neuroimaging in posttraumatic stress disorder and other stress-related disorders. Neuroimaging Clinics of North America $17(4), 523-538$, ix

Breslau, N., \& Davis, G. C. (1992). Postraumatic stress disorder in an urban population of young adults: Risk factors for chronicity. American Journal of Psychiatry, 149, 671-675.

Breslau, N., Chilcoat, H. D., Kessler, R. C., \& Davis, G. C. (1999) Previous exposure to trauma and PTSD effects of subsequent trauma: Results from the Detroit Area Survey of Trauma. American Journal of Psychiatry, 156(6), 902-907.

Breslau, N., Kessler, R. C., Chilcoat, H. D., Schultz, L. R., Davis, G. C., \& Andreski, P. (1998). Trauma and posttraumatic stress disorder in the community: The 1996 Detroit Area Survey of Trauma. Archives of General Psychiatry, 55(7), 626-632.

Brewin, C. R. (2001). A cognitive neuroscience account of posttraumatic stress disorder and its treatment. Behaviour Researc and Therapy, 39(4), 373-393.

de Quervain, D. J.-F., Kolassa, I.-T., Ertl, V., Onyut, P. L., Neuner, F. Elbert, T., \& Papassotiropoulos, A. (2007). A deletion variant of the alpha $2 b$-adrenoceptor is related to emotional memory in Europeans and Africans. Nature Neuroscience, 10(9), 1137-1139.

Dohrenwend, B. P., Turner, J. B., Turse, N. A., Adams, B. G., Koenen, K. C., \& Marshall, R. (2006). The psychological risks of Vietnam for U.S. veterans: A revisit with new data and methods. Science, 313(5789), 979-982.

Dunmore, E., Clark, D. M., \& Ehlers, A. (2001). A prospective examination of the role of cognitive factors in persistent postraumatic stress disorder (PTSD) after physical or sexual assault. Behaviour Research and Therapy, 39, 1063-1084.

Eckart, C., Engler, H., Riether, C., Elbert, T., \& Kolassa, I.-T. (2009). No PTSD-related differences in diurnal cortisol profiles of genocide survivors. Psychoneuroendocrinology, 34, 523-531.

Edwards, V. J., Holden, G. W., Felitti, V. J., \& Anda, R. F. (2003) Relationship between multiple forms of childhood maltreatment and adult mental health in community respondents: Results from the adverse childhood experiences study. American Journal of Psychiatry, I60(8), 1453-1460.

El Sarraj, E., Punamäki, R.-L., Salmi, S., \& Summerfield, D. (1996). Experiences of torture and ill-treatment and posttraumatic stress disorder symptoms among Palestinian political prisoners. Journal of Traumatic Stress, 9(3), 595-606.

Elbert, T., Rockstroh, B., Kolassa, I.-T., Schauer, M., \& Neuner, F. (2006). The influence of organized violence and terror on brain and mind-A co-constructive perspective. In P. Baltes, P. Reuter-Lorenz, \& F. Rösler (Eds.), Lifespan development and the brain: The perspective of biocultural co-constructivism (pp. 326-349). Cambridge, England: Cambridge University Press.

Elbert, T., \& Schauer, M. (2002). Burnt into memory. Nature, 419, 883. Ertl, V. (2008). Validierung westlicher Konzepte zur Erfassung psychis. chen Leids in Afrika. Reliabilität und Validität der Erfassung posttraumatischer Belastungsstörung in einer ostafrikanischen Flüchtlingssiedlung. Saarbrücken, Germany: VDM Verlag Dr. Müller.

Ertl, V., Pfeiffer, A., Saile, R., Schauer, E., Elbert, T., \& Neuner, F. (in press). Validation of a mental health assessment in an African conflict population. Psychological Assessment.

Foa, E. B., Cashman, L., Jaycox, L., \& Perry, K. (1997). The validation of a self-report measure of posttraumatic stress disorder: The Posttraumatic Diagnostic Scale. Psychological Assessment, 9, 445-451.

Foa, E. B., \& Kozak, M. J. (1986). Emotional processing of fear: Exposure to corrective information. Psychological Bulletin, 99(1), 20-35.

Foa, E. B., \& Riggs, D. S. (1993). Posttraumatic stress disorder in rape victims. In J. Oldham, M. B. Riba, \& A. Tasman (Eds.), American Psychiatric Press review of psychiatry (Vol. 12, pp. 273-303). Washington, DC: American Psychiatric Press.

Follette, V. M., Polusny, M. A., Bechtle, A. E., \& Naugle, A. E. (1996). 
Cumulative trauma: The impact of child sexual abuse, adult sexual assault, and spouse abuse. Journal of Traumatic Stress, 9(1), 25-35.

Good, P. I. (2005). Permutation, parametric, and bootstrap tests of hypotheses. New York, NY: Springer.

Green, B. L., Goodman, L. A., Krupnick, J. L., Corcoran, C. B., Petty, R. M., Stockton, P., \& Stern N. M. (2000). Outcomes of single versus multiple trauma exposure in a screening sample. Joumal of Traumatic Stress, 13(2), 271-286.

Harrell, F. E. (2001). Regression modeling strategies. New York, NY: Springer.

Johnson, H., \& Thompson, A. (2008). The development and maintenance of post-traumatic stress disorder (PTSD) in civilian adult survivors of war trauma and torture: A review. Clinical Psychology Review, 28, 36-47.

Karamustafalioglu, O. K., Zohar, J., Guveli, M., Gal, G., Bakim, B., Fostick, L., Karamustafalioglu, N., \& Sasson, Y. (2006). Natural course of posttraumatic stress disorder: A 20-month prospective study of Turkish earthquake survivors. Journal of Clinical Psychiatry, 67(6), 882889.

Kolassa, I.-T., Burla, A., Schauer, M., \& Elbert, T. (). Das Furchtnetzwerk in der Posttraumatischen Belastungsstörung: Bildung und potentielle Reaktivierung. Verhaltenstherapie.

Kolassa, I.-T., \& Elbert, T. (2007). Structural and functional neuroplasticity in relation to traumatic stress. Current Directions in Psychological Science, 16(6), 321-325.

Kolassa, I.-T., Ertl, V., Eckart, C., Glöckner, F., Kolassa, S., Papassotiropoulos, A., et al. (2010a). Association study of trauma load and SLC6A4 promoter polymorphism in PTSD; Evidence from survivors of the Rwandan genocide. Journal of Clinical Psychiatry, 71, 543-547.

Kolassa, I.-T., Ertl, V., Kolassa, S., Papassotiropoulos, A., \& de Quervain, D. J.-F. (2010b). The risk of Posttraumatic Stress Disorder after trauma depends on trauma load and the COMT Val158Met polymorphism. Biological Psychiatry, 67(4), 304-308.

Lang, A. J., Stein, M. B., Kennedy, C. M., \& Foy, D. W. (2004). Adult psychopathology and intimate partner violence among survivors of childhood maltreatment. Joumal of Interpersonal Violence, $19(10)$, $1102-1118$

Lang, P. J. (1979). Presidential address, 1978. A bio-informational theory of emotional imagery. Psychophysiology, 16(6), 495-512.

Lang, P. J. (1984). Dead souls: Or why the neurobehavioral science of emotion should pay attention to cognitive science. In T. Elbert, B. Rockstroh, \& N. Bierbaumer (Eds.), Self-regulation of the brain and behavior (pp. 255-272). Berlin, Germany: Springer.

McCauley, J., Kern, D. E., Kolodner, K., Dill, L., Schroeder, A. F. DeChant, H. K., Ryden, J., Derogatis, L. R., \& Bass, E. B. (1997) Clinical characteristics of women with a history of childhood abuse Unhealed wounds. JAMA, 277(17), 1362-1368.

McNally, R. J. (2003). Progress and controversy in the study of Posttraumatic Stress Disorder. Annual Review of Psychology, 54, 229-252.

McNally, R. J. (2006). Cognitive abnormalities in posttraumatic stress disorder. Trends in Cognitive Sciences, 10, 271-277.

Metcalfe, J., \& Jacobs, W. J. (1996). A "hot-system/cool-system" view of memory under stress. PTSD Research Quarterly, 7(2), 1-3.
Mollica, R. F., McInnes, K., Pham, T., Smith Fawzi, M. C., Murphy, E., \& Lin, L. (1998). The dose-effect relationships between torture and psychiatric symptoms in Vietnamese ex-political detainees and a comparison group. The Journal of Nervous and Mental Disease, 186(9), 543 553.

Mollica, R. F., McInnes, K., Poole, C., \& Tor, S. (1998). Dose-effect relationships of trauma to symptoms of depression and post- traumatic stress disorder among Cambodian survivors of mass violence. British Journal of Psychiatry, 173, 482-488.

Neuner, F., Onyut, L. P., Ertl, V., Odenwald, M., Schauer, E., \& Elbert, T. (2008). Treatment of posttraumatic stress disorder by trained lay counselors in an African refugee settlement: A randomized controlled trial. Journal of Consulting and Clinical Psychology, 76(4), 686-694.

Neuner, F., Schauer, M., Karunakara, U., Klaschik, C., Robert, C., \& Elbert, T. (2004). Psychological trauma and evidence for enhanced vulnerability for posttraumatic stress disorder through previous trauma among West Nile refugees. BMC Psychiatry, 4, 34.

North, C. S., Smith, E. M., \& Spitznagel, E. L. (1997). One-year follow-up of survivors of a mass shooting. American Journal of Psychiatry, 154, $1696-1702$.

Onyut, L. P., Neuner, F., Ertl, V., Schauer, E., Odenwald, M., \& Elbert, T. (2009). Trauma, poverty and mental health among Somali and Rwandese refugees living in an African refugee settlement - an epidemiological study. Conflict and Health, 3, 6.

Onyut, L. P., Neuner, F., Schauer, E., Ertl, V., Odenwald, M., Schauer, M. \& Elbert, T. (2004). The Nakivale Camp Mental Health Project: Building local competency for psychological assistance to traumatised refugees. Intervention, 2(2), 90-107.

Perkonigg, A., Pfister, H., Stein, M. B., Hofler, M., Lieb, R, Maercker, A. \& Wittchen, H. U. (2005). Longitudinal course of posttraumatic stress disorder and posttraumatic stress disorder symptoms in a community sample of adolescents and young aduits. American Journal of Psychiatry, $162(7), 1320-1327$.

R Development Core Team. (2008), R: A language and environment for statistical computing (Version 2.8.1) [Computer software].

Rauch, S. L., Shin, L. M., \& Phelps, E. A. (2006). Neurocircuitry model of posttraumatic stress disorder and extinction: Human neuroimaging research-past, present, and future. Biological Psychiatry, 60(4), 376382

Schauer, M., Neuner, F., Karunakara, U., Klaschik, C., Robert, C., \& Elbert, T. (2003). PTSD and the "building block" effect of psychological trauma among West Nile Africans. ESTSS (European Society for Traumatic Stress Studies) Bulletin, 10(2), 5-6.

Zlotnick, C., Rodriguez, B. F, Weisberg, R. E., Bruce, S. E., Spencer, M. A., Culpeper, L., \& Keller, M. B. (2004). Chronicity in postraumatic stress disorder and predictors over the course of postraumatic stress disorder among primary care patients. The Journal of Nervous and Mental Disease, 192(2), 153-159. 